\title{
Online Customer Care: An Android Application for Mobile Customers using Speech Synthesis
}

\author{
Keshav Singh Rana \\ Thapar University \\ Patiala (Punjab), India
}

\author{
Rupinderdeep Kaur \\ Lecturer \\ Thapar University Patiala \\ (Punjab), India
}

\begin{abstract}
In the past decade, demand for mobile phones has seen a consistent rise if other portable computing devices taken into consideration. When confronted with a query, people first take out their mobile phones with internet connections instead of going for other options such as Laptops or PCs. When it comes to software development, the first choice of a developer would be Android OS because of its open source licensing and the sheer number of users all over the world. Text to speech is a process of generating speech by a device on the basis of input text. The focus of a proposed work is to develop an application for mobile customers who are unable to get solution to their problems because of the language barriers. Many companies do provide support for regional languages to solve their customer's issues, however they haven't yet developed a software application for Hindi. So, a questionnaire is formed on the basis of frequently asked questions by mobile customers and created a database as a solution for both English and Hindi. Speech synthesis will have an important role for the people with sight disabilities.
\end{abstract}

\section{Keywords}

Text-to-Speech conversion (TTS), Speech synthesis, Concatenative speech, Android OS

\section{INTRODUCTION}

Speech recognition technique has been broadly look into from the past four or five decades because of its high degree adoption. Speech is esteemed to be one of the simplest and reliable means of communication. It is an effective way to recognize people on the basis of speech. To deliver any information from man to machine, different things like keypad, human interface devices are required which is not favorable for everyone as it needs special skills. So, speech has offered a good platform to solve this problem

Text to Speech is a prime application of natural language processing (NLP).TTS is a speech form which converts a text into spoken voice. A block diagram of TTS system is shown in figure 1. Concatenative speech synthesis has become very popular in recent years due to its improved sensitivity to unit context over simpler predecessors. It is a NLP constituent that gives easy communication for the person who is not able to speak but can communicate verbally and for those who can't understand English language.

A survey of 25-30 papers of this topic is doneby considering what work under android platform has already been done and how to help people to minimize the communication gap and help them to solve their problems.

Android OS has become very popular in recent times. The android devices also assist the text-to-speech synthesis. Therefore, speech synthesis has turn to be a crucial modality on mobile devices as various characteristics like running, driving which curb the use of visual modality. Speech synthesis system for mobiledevices are not an easy job as it has a small-scale storage capacity andperformance. An android architecture [17] is shown in figure 2.

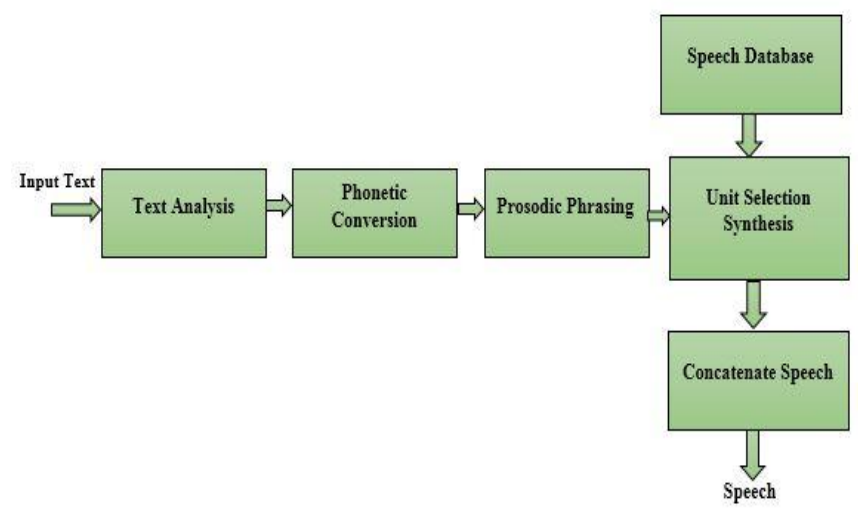

Fig 1: Block Diagram of Text to Speech [28]

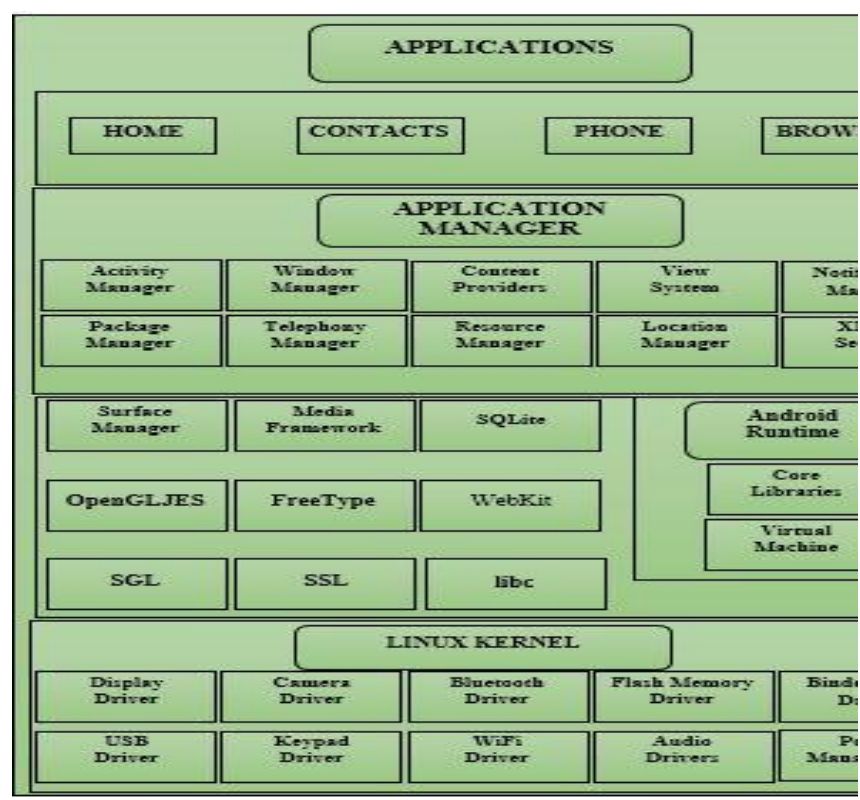

Fig2: Android Architecture [17]

\section{LITERATURE SURVEY}

Devika Sharma, Kanwar Ranju [1] created a language translator that takes an input text, split up into individual words and after the identification w.r.t their phonetic factor. It connects with the library to find out the voice representation of that specific word. Furthermore the text is translate from 
one regional language to another with respect to the voice representation.

Mhamunkar, Priyanka V. et al.[2] created an application in which the user and the server are interacting in voice-to-text and text-to-voice form. Voice is converted into text and that text is searched in the dictionary present in application already and take out its meaning, which later will be converted into voice.

Sangle, Shailesh S., Nilesh M. Patil [3] created a social domain based application. They developed a system and combines voice synthesis with skype. It gives a person an ease who is having sound disorder to talk with another person localize anywhere in the world by removing a hurdle that creates a problem during phone call.

Kamble et al.[4] presented single text-to-speech system for Hindi language to generate speech. Two steps is been followed, processing of text and generating speech. To convert Hindi text to speech, a graphical user interface has been designed in java swings [4]. Concatenative speech synthesis approach is been used.

Hansen, John Paulinet al.[5] built a Bluetooth platform that contains audio messages, near about information and one sided text-to-speech paging with the help of smart phones or it is a hardware that people might carry with them as well. This handy device plays an important role in places like shopping centers, hospitals and airports.

Subhaashiniet al.[6] developed an android based application for ease communication between normal and hearing disable persons. As sign languages are mostly used by these persons. So, this application converts those sign languages into speech sound which later can easily be understand by the people who has no knowledge regarding this sign language.

Duke, I. et al. [7] presented a keyboard which is a combination of physical and gestural keyboards. They made an 8-button keyboard named Braille that can be connected to the smart phones via input wire. On the other side, the touchscreen endow gestures like thumb click for more difficult text editing operations. They help and gives economic and useful experience for users having sight problems.

Landicho, Junar A et al.[8] developed an application for the communication between two person both having problems like hearing and visual. Some of the keen features of this application are sending, replying, forwarding as it is a text based application.

In this paper, Miyabe Maiet al.[9] created a support system for medical domain. They developed a system to minimize the communication gap that arises because of not understanding a foreign language. It provides a function by which foreign patients will face no problem during communicating with the local receptionist. This system supports Japanese and English.

Aakash Agarwal [10] created an application which calculate the visual power of a patient. Its work is similar to that of an ophthalmologist who checks an eyesight with the help of a Snellen chart. The visual sense is calculated by means of textto-speech conversion. Questionnaire is also followed after calculation, which uses Web Ontology Language (OWL).

Kuei-Chun Liu,et al.[11] developed an application for the visually disable persons, who need helpful tools to aviate digital devices. By that, these people will get the digital information while working, living and learning. They developed an assistive system for those who faces visual problems during the use of android devices.

Felix Burkhardt [12] created an application by keeping in mind a main target that is a car domain. A system is developed for office mobile and entertainment stuff. The input function consist of a touch screen and automatic speech acknowledgement and the output consist of a screen and speech synthesis.

GaurangKanvinder [13] developed an android based application for education domain. They developed an e-book reader for this platform but in a more handy way. It makes an ease for the people who are suffering from dyslexia. It contains the features that combines with already made functions that is text-to-speech technology and displaying the text in more orient way.

In this paper, Sankar Mukherjee and Shyamal Kumar Das Mandal [14] implemented a Bengali speech synthesizer for a mobile devices. For generating the speech, they used ESNOLA (Epoch Synchronous Non- Overlap Add) which is a concatenate based speech technique.

Jagmeet Kaur and Parminder Singh [15] developed a Punjabi speech synthesizer that gives an output speech on a mobile device. Concatenative based speech synthesis approach is used which uses the phonemes for concatenate process.

Arun Gopi and Shobana Devi P [16] developed an android based application by using ESNOLA (Epoch Synchronous Non-Overlap Add) technique for Malayalam language. It is based on a concatenative based speech synthesis technique. They also apprise the implementation of Malayalam TTS, generate the database and access the database. It also manages the Malayalam character showing in android devices.

Sanja Primoracet al. [17] created an application named Voice SMS in which the spoken messages is converted into text form messages. Users are able to send those messages to their contact list. Speech recognition uses HMM (Hidden Markov Model) technique which is a most adaptable approach in speechrecognition.

Ravina Mithe, et al.[18] developed an application which execute image to speech conversion using android platform. The OCR (Optical Character Recognition) takes an image as an input, extract the text from that image and then convert that text into speech form.

In this paper, Angelov, Krasimir et al. [19] presented an architecture for speech-to-speech translation on android devices which is based on Grammatical Framework (GF). The architecture is to avail for language-controlled like translator that gives very high quality, which is a strong point of GF.

Thad Hughes, Kaisuke Nakajima et al.[20] presented a system for creating transcribed speech corpora having an utterances that is recorded by various speakers in different acoustic conditions. This system is having a client application running on an android based mobile phones with internet connection in it. This application collects the information about the speaker, get the textual prompts from the server to read by the speaker, record the voice of a speaker and upload the audio and its metadata to the server.

Paulo A. Condado et al.[21] created an android based speech synthesis system that act as an interface between two different versions of information, known text-to-speech, to play effective communication between two people. The application developed is reliable and user friendly and also an effective 
communication is performed. Zhuorui Yang et al.[22] developed an android based application that helps visual disable persons to cognize U.S banknotes. The application doesn't require any wireless connectivity or any infrastructure as it only rely on an android smartphones.

Ronald $\mathrm{Yu}$ et al.[23] designed and implemented an android application that makes a 3-dimensional model of a human head exalt the lip movement of the human speech from the text input. The application uses an android text to speech engine to convert the text which is entered by the user in a text box to human speech form in English.

S. Saychumet al. [24] developed a system consist of a Thai text processor along with the English text processor which inspects English text at high understandability. By using HMM based speech unit and audio streaming optimization, it converts highly smooth sound at a fast speed. CRF
(Conditional Random Field) approach is used for the segmentation of Thai words.

Yu Zhong [25] in 2014, developed this application construct a set of voices based on the context of an application, the commands are synthesized in a straight way from on-screen labels and accessibility parts of data. JustSpeak can remarkably improves the graphical interface for blind and gesture impaired people.

Amanda J. Stent and Shiri Azenkot [26] developed an iWalk application that helps people having vision problems. It is talk enable application that search the local places and gives navigation (directions) for needy person. It runs on smart phones. It assist speech input and gives live directions in both speech and text using information for time-to-turn with respect to street names so that the user has no need to look over to the street signs.

Table 1.Summary of different applications develop under an android platform

\begin{tabular}{|c|c|c|c|}
\hline S. No & Domain & Language & Overview \\
\hline 1. & Social Help & $\begin{array}{l}\text { English, } \\
\text { Hindi,French, } \\
\text { German }\end{array}$ & $\begin{array}{l}\text { Devika Sharma and Ranju Kanwar [1] created a language } \\
\text { translator that takes an input text, split up into individual words } \\
\text { and after the identification w.r.t their phonetic factor. It connects } \\
\text { with the library to find out the voice representation of that } \\
\text { specific word. Furthermore the text is translate from one regional } \\
\text { language to another with respect to the voice representation. }\end{array}$ \\
\hline 2. & Education & English & $\begin{array}{l}\text { Mhamunkar, Priyanka V. et. al[2] created an application in } \\
\text { which the user and the server are interacting in voice-to-text and } \\
\text { text-to-voice form. Voice is converted into text and that text is } \\
\text { searched in the dictionary present in application already and take } \\
\text { out its meaning, which later will be converted into voice. }\end{array}$ \\
\hline 3. & Social Help & English, Hindi & $\begin{array}{l}\text { Sangle, Shailesh S. and Nilesh M. Patil [3] created a social } \\
\text { domain based application. They developed a system and } \\
\text { combines voice synthesis with skype. It gives a person an ease } \\
\text { who is having sound disorder to talk with another person localize } \\
\text { anywhere in the world by removing a hurdle that creates a } \\
\text { problem during phone call. }\end{array}$ \\
\hline 4. & Social Help & English, Hindi & $\begin{array}{l}\text { Kamble et. al [4] presented single text-to-speech system } \\
\text { forlanguage Hindi to generate speech. Two steps is been } \\
\text { followed, processing of text and generating speech. To convert } \\
\text { Hindi text to speech, a graphical user interface has been designed } \\
\text { in java swings [4]. Concatenative speech synthesis approach is } \\
\text { been used. }\end{array}$ \\
\hline 5. & Indoor Help & English & $\begin{array}{l}\text { Hansen and John Paulin [5] built a Bluetooth platform that } \\
\text { contains audio messages, near about information and one sided } \\
\text { text-to-speech paging with the help of smart phones or it is a } \\
\text { hardware that people might carry with them as well. This handy } \\
\text { device plays an important role in places like shopping centers, } \\
\text { hospitals and airports. }\end{array}$ \\
\hline 6. & Social Help & English & $\begin{array}{l}\text { Subhaashini } \text { et. al [6] developed an android based application for } \\
\text { ease communication between normal and hearing disable } \\
\text { persons. As sign languages are mostly used by these persons. So, } \\
\text { this application converts those sign languages into speech sound } \\
\text { which later can easily be understand by the people who has no } \\
\text { knowledge regarding this sign language. }\end{array}$ \\
\hline 7. & Social Help & English & $\begin{array}{l}\text { Duke, I. et. al [7] presented a keyboard which is a combination } \\
\text { of physical and gestural keyboards. They made an 8-button } \\
\text { keyboard named Braille that can be connected to the smart } \\
\text { phones via input wire. On the other side, the touchscreen endow } \\
\text { gestures like thumb click for more difficult text editing }\end{array}$ \\
\hline
\end{tabular}




\begin{tabular}{|c|c|c|c|}
\hline & & & $\begin{array}{l}\text { operations. They help and gives economic and useful experience } \\
\text { for users having sight problems. }\end{array}$ \\
\hline 8. & Social Help & English & $\begin{array}{l}\text { Landicho and Junar A [8] developed an application for } \\
\text { thecommunication between two person both having problems } \\
\text { like hearing and visual. Some of the keen features of this } \\
\text { application are sending, replying, forwarding as it is a text based } \\
\text { application. }\end{array}$ \\
\hline 9. & Medical & $\begin{array}{l}\text { English, } \\
\text { Japanese }\end{array}$ & $\begin{array}{l}\text { In this paper, Miyabe Mai et. al [9] developed a support system } \\
\text { for medical domain. They developed a system to minimize the } \\
\text { communication gap that arises because of not understanding a } \\
\text { foreign language. It provides a function by which foreign } \\
\text { patients will face no problem during communicating with the } \\
\text { local receptionist. This system supports Japanese and English } \\
\text { languages. }\end{array}$ \\
\hline 10. & Medical & English & $\begin{array}{l}\text { Aakash Agarwal [10] created an application which calculate the } \\
\text { visual power of a patient. Its work is similar to that of an } \\
\text { ophthalmologist who checks an eyesight with the help of a } \\
\text { Snellen chart. The visual sense is calculated by means of text-to- } \\
\text { speech conversion. Questionnaire is also followed after } \\
\text { calculation, which uses Web OntologyLanguage (OWL). }\end{array}$ \\
\hline 11. & Social Help & English & $\begin{array}{l}\text { Kuei-Chun Liu, et. al [11] developed an application for the } \\
\text { visually disable persons, who need helpful tools to aviate digital } \\
\text { devices. By that, these people will get the digital information } \\
\text { while working, living and learning. They developed an assistive } \\
\text { system for those who faces visual problems during the use of } \\
\text { android devices. }\end{array}$ \\
\hline 12. & Corporate & $\begin{array}{l}\text { English, } \\
\text { German }\end{array}$ & $\begin{array}{l}\text { Felix Burkhardt } e t \text {. al [12] created an application by keeping in } \\
\text { mind a main target that is a car domain. A system is developed } \\
\text { for office mobile and entertainment stuff. The input function } \\
\text { consist of a touch screen and automatic speech } \\
\text { acknowledgement and the output consist of a screen and speech } \\
\text { synthesis. }\end{array}$ \\
\hline 13. & Education & English & $\begin{array}{l}\text { Gaurang Kanvinder [13] developed an android based application } \\
\text { for education domain. They developed an e-book reader for this } \\
\text { platform but in a more handy way. It makes an ease for the } \\
\text { people who are suffering from dyslexia. It contains the features } \\
\text { that combines with already made functions that is text-to-speech } \\
\text { technology and displaying the text in more orient way. }\end{array}$ \\
\hline 14. & Social Help & $\begin{array}{l}\text { English, } \\
\text { Bengali }\end{array}$ & $\begin{array}{l}\text { In this paper, Sankar Mukherjee and Shyamal Kumar Mandal } \\
\text { [14] implemented a speech synthesizer for Bengali language for } \\
\text { mobile devices. For generating the speech, they used ESNOLA } \\
\text { (Epoch Synchronous Non- Overlap Add) which is a concatenate } \\
\text { based }\end{array}$ \\
\hline 15. & Social Help & $\begin{array}{l}\text { English, } \\
\text { Punjabi }\end{array}$ & $\begin{array}{l}\text { Jagmeet. Kaur and Parminder Singh [15] developed a Punjabi } \\
\text { speech synthesizer that gives a speech output on mobile devices. } \\
\text { Concatenative based speech synthesis approach is used which } \\
\text { uses the phonemes for concatenate process. }\end{array}$ \\
\hline 16. & Social Help & Malayalam & $\begin{array}{l}\text { Arun Gopi et. al[16] Developed an android based application by } \\
\text { using ESNOLA (Epoch Synchronous Non-Overlap Add) } \\
\text { technique for Malayalam language. It is based on a } \\
\text { concatenative based speech synthesis technique. They also } \\
\text { apprise the implementation of Malayalam TTS, generate the } \\
\text { database and access the database. It also manages the Malayalam } \\
\text { character showing in android devices. }\end{array}$ \\
\hline 17. & Communication & English & $\begin{array}{l}\text { Sanja Primorac et. al[17] created an application named Voice } \\
\text { SMS in which the spoken messages is converted into text form }\end{array}$ \\
\hline
\end{tabular}




\begin{tabular}{|c|c|c|c|}
\hline & & & $\begin{array}{l}\text { messages. Users are able to send those messages to their contact } \\
\text { list. Speech recognition uses HMM (Hidden Markov Model) } \\
\text { technique which is a successful and most adaptable approach in } \\
\text { speech recognition. }\end{array}$ \\
\hline 18. & $\begin{array}{l}\text { Banking, } \\
\text { Corporate }\end{array}$ & English & $\begin{array}{l}\text { Ravina Mithe et. al }[18] \text { developed an application which execute } \\
\text { image to speech conversion using android platform. The OCR } \\
\text { (Optical Character Recognition) takes an image as an input, } \\
\text { extract the text from that image and then convert that text into } \\
\text { speech }\end{array}$ \\
\hline 19. & Social Help & $\begin{array}{c}\text { English, } \\
\text { French, Italian }\end{array}$ & $\begin{array}{l}\text { In this paper, Angelov and Krasimir [19] presented an } \\
\text { architecture for speech-to-speech translation on android devices } \\
\text { which is based on Grammatical Framework (GF). The } \\
\text { architecture is to avail for language-controlled like translator that } \\
\text { gives very high quality, which is a strong point of GF. }\end{array}$ \\
\hline 20. & Social Help & 17 Languages & $\begin{array}{l}\text { Thad Hughes et. al [20] presented a system for creating } \\
\text { transcribed speech corpora having an utterances that is recorded } \\
\text { by various speakers in different acoustic conditions. This system } \\
\text { is having a client application on an android based mobile phones } \\
\text { with internet connection in it. This application collects the } \\
\text { information about the speaker, get the textual prompts from the } \\
\text { server to read by the speaker, record the voice of a speaker and } \\
\text { upload the audio and its metadata to the server. }\end{array}$ \\
\hline 21. & Social Network & English & $\begin{array}{l}\text { Paulo A. Condado et. al [21] created an android based speech } \\
\text { synthesis system that act as an interface between two different } \\
\text { versions of information, known text-to-speech, to play effective } \\
\text { communication between two people. The application developed } \\
\text { is reliable and user friendly and also an effective communication } \\
\text { is performed. }\end{array}$ \\
\hline 22. & Banking & English(U.S) & $\begin{array}{l}\text { Zhuorui Yang et. al[22] developed an android based application } \\
\text { that helps visual disable persons to cognize U.S banknotes. The } \\
\text { application doesn't require any wireless connectivity or any } \\
\text { infrastructure as it only rely on an android smartphones. }\end{array}$ \\
\hline 23. & Animation & English & $\begin{array}{l}\text { Ronald Yu et. al [23] designed and implemented an android } \\
\text { application that makes a 3-dimensional model of a human head } \\
\text { exalt the lip movement of the human speech from the text input. } \\
\text { The application uses an android text to speech engine to convert } \\
\text { the text which is entered by the user in a text box to human } \\
\text { speech form in English. }\end{array}$ \\
\hline 24. & Social Help & English, Thai & $\begin{array}{l}\text { S. Saychum et. al [24] developed a system consist of a Thai text } \\
\text { processor along with the English text processor which inspects } \\
\text { English text at high understandability. By using audio streaming } \\
\text { optimizationandHMM based speech unit, it converts highly } \\
\text { smooth sound at a fast speed. CRF (Conditional Random Field) } \\
\text { approach is used for the segmentation of Thai words. }\end{array}$ \\
\hline 25. & Social Help & English & $\begin{array}{l}\text { Yu Zhong et. al [25] in 2014, developed this application } \\
\text { construct a set of voices based on the context of an application, } \\
\text { the commands are synthesized in a straight way from on-screen } \\
\text { labels and accessibility parts of data. }\end{array}$ \\
\hline 26. & Social Help & English & $\begin{array}{l}\text { Amanda J. et. al[26] developed an iWalk application that helps } \\
\text { people having vision problems. It is talk enable application that } \\
\text { search the local places and gives navigation (directions) for } \\
\text { needy person. It runs on smart phones. It assist speech input and } \\
\text { gives live directions in both speech and text using information } \\
\text { for time-to-turn with respect to street names so that the user has } \\
\text { no need to look over to the street signs. }\end{array}$ \\
\hline
\end{tabular}




\section{SYSTEM DESIGN}

Developed an application to give an effective language translator in android phones which will help hand-help device users. People are still lacking in both, understanding and communicating in English language. A mobile customer care still handling user problems in telephony way, in text form it is only available in one that is English language. People might not get the perfect solution by customer care via telephony way, so a questionnaire database is created that surely helps them. A lot of complaints on the internet regarding mobile operator issues and popped out the top questions, figure out the best possible solutions and then make a questionnaire by them. So, the work is to make an ease for the users to get the solutions in quick and understanding manner. As Hindi is the most understandable language among all the languages for people. So, an android based application is developed that is having questionnaire regarding mobile customer problems.

- Concatenate speech synthesis approach was chosen to get an instinctive quality in synthetic speech.

- For speech synthesis, phonemes is used of the English language as a primary element.

- By using these phonemes, a speech database is created for English language questionnaire.

- For Hindi language, a translator is doing a job for translating English text to Hindi text.

- Later, the connectivity of the questionnaire for both the languages is done to make an ease for the user.

- Phonemes were looking for in the database and its related phoneme sounds were concatenated to produce a speech.

\subsection{Why Telecom?}

In consumerforum.in [27] a chart is given in figure 3 that shows a complaint volume by different industries. By seeing, it shows that the Telecom companies forms a disproportionality by a large number.

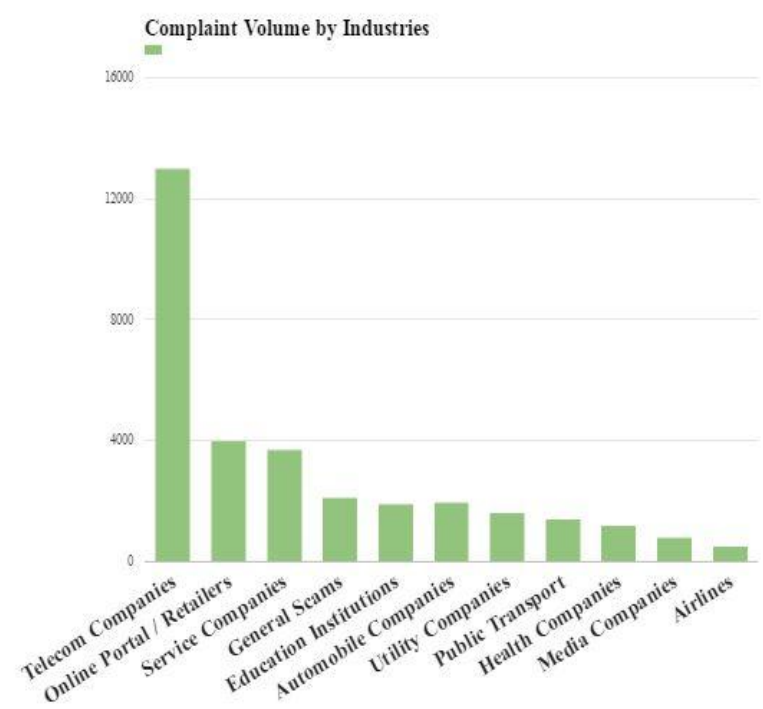

Fig 3: Complaint volume statistics [27]

\subsection{Flow Chart}

The step to step procedure of the overall work of an application is shown in the given flow chart shown in figure 4 .

\subsection{Proposed Work}

After it starts, it first displays an English question as a query. If a user is looking for some other problem solution, then user needs to search it in a database for that particular problem. The Translator Button translates the given English input query into Hindi language format so as for the answer as well. Speech synthesis is performed accordingly to the need of the user by using Speech Button.

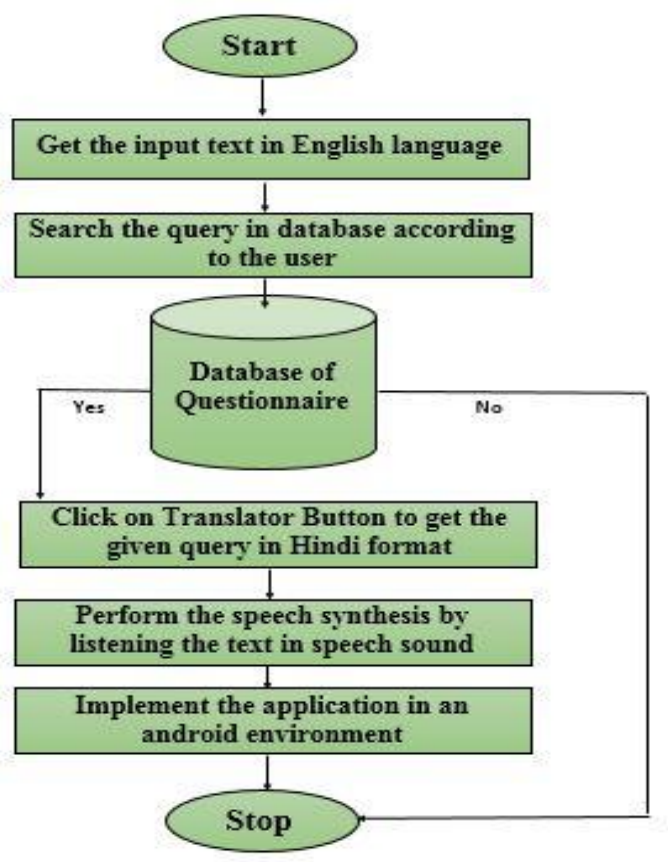

Fig 4: Flow Chart

\subsection{An Application View}

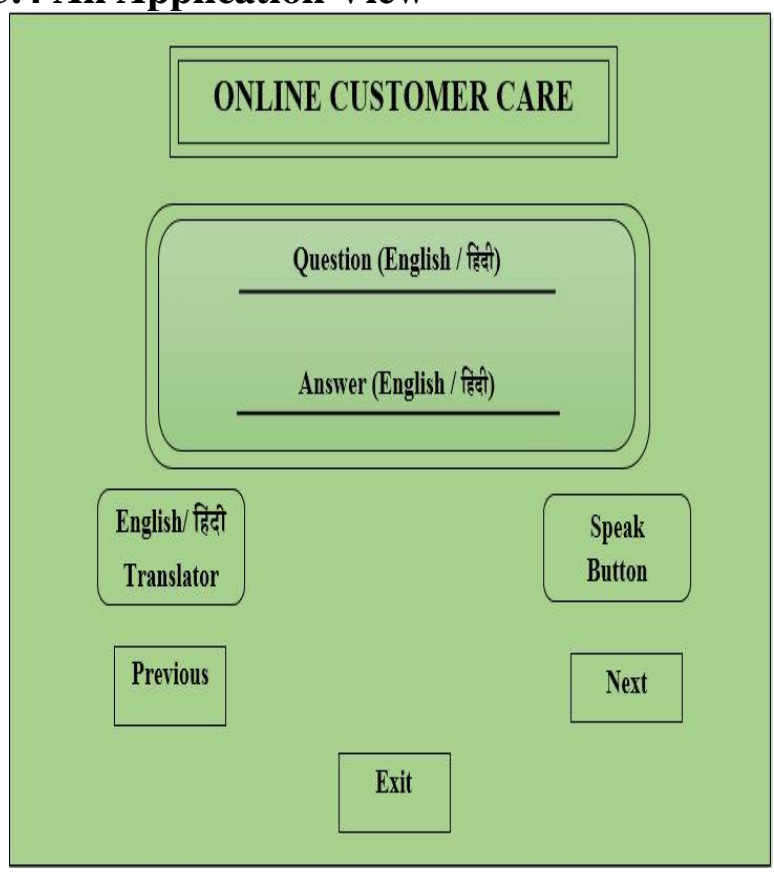

Fig5: Front View

\subsubsection{Steps of Implementation}

- Firstly, design a structure for operation buttons that would be the overall operational view of the application. 
- After getting the operations, start designing and placing of operation buttons in a meaningful places. By that, front end is ready.

- Now, the database (back end) work is started and also starts collecting questionnaire according to the highness of the problem that mostly user faced in day to day life.

- According to those questionnaire, voices are recorded in Hindi language which is audible and easily be understand by the people, as English voices is inbuilt in an application itself.

- Now, looping and connectivity part of the text and its related speech sound is maintained accordingly, so that it will be an ease for the user to get a solution in a quick and easy way.

- Buttons like Hindi/English Translator, Speech, Previous, Next and Exit shows in the front view of figure 5 works accordingly to the need of the user and their problem, means what query a user wants is just under one click.

- Action of buttons are very important and in a sequence way that means you need to translate first, then use the speech button to listen to the problem solution in Hindi language.

\section{CONCLUSION}

In this research work, the text to speech conversion with intermediate language translator shows the useful result. The translation of language was done by Microsoft translator API. The voice is hearable with paragraphs and punctuation ambiguity [9]. Latest speech recognition API's are only having the capability for recognize a single word. It will raise the speech recognition to recognize a sentence. The cloudbased translation system used here for English-Hindi language. It helps for blind persons to hear the solutions of the problems after text is converted into speech. Time consumption will also be reduced that before was taken a lot of time during conversation between the customer and operator. The conversion of text-to-speech has been done for English and Hindi language. The individual not only able to hear the text but also can read the translated text with that of the language translator. It can also be done for rest of the regional languages as well as foreign language.

\section{FUTURE SCOPE}

An application of speech synthesis have been developed for android platform. The developed application is reliable and user friendly and performed an impressive communication. This system can be a problem solution for the people and specially targeting to those with audible problems as it would help them to listen to their problems that they faced regarding their mobile operators. The application work has been done for English and Hindi language. In future, this work can also be done for rest of the regional languages like Gujarati, Tamil, Telugu, etc.

\section{REFERENCES}

[1] Devika Sharma and Ranju Kanwar, "Text to Speech Conversion with Language Translator under Android Environment." (2015).

[2] Miss. Priyanka V. Mhamunkar, Mr. Krishna S. Bansode and Prof. Laxman S. Naik "Android Application to get. Word Meaning through Voice." International Journal of
Advanced Research in Computer Engineering \& Technology (IJARCET) 2.2 (2013): pp-572.

[3] Shailesh S. Singla and Nilesh M. Patil "Speech Synthesis Using Android". International Journal of Innovative Research and Development (2014).

[4] Kamble, Kaveri, and Ramesh Kagalkar. "A Review: Translation of Text to Speech Conversion for Hindi Language." International Journal of Science and Research (IJSR) Volume 3.

[5] Hansen, John Paulin, Wang Wusheng, and Irina Shklovski. "Talkingbadge demo." Proceedings of the 7th Nordic Conference on Human-Computer Interaction: Making Sense through Design. ACM, 2012.

[6] G.V.S Subhaashini, S. Divya, S. DivyaSuganya, Tharni Vimal "Ear Hear Android Application for specially Abled Deaf People." International Journal of Computer Science and Engineering 3.3 (2015): 1108-1114.

[7] Duke, I., Hugo Nicolau, and Vicki L. Hanson. "mBrailler: Multimodal Braille Keyboard for Android." (2016).

[8] Junar A. Landicho, Dimful D. Benantolis, Rex Gil R. Cabason, Mark Lorenz G. Ramos, and Lux Justine B. Sonquipal "Voisee Communicator: An Android Mobile Application for Deaf-Mute and Blind Communications." (2015).

[9] Miyabe Mai, and Takashi Yoshino "Development of multilingual medical reception support system with text-to-speech function to combine utterance data with voice synthesis." Proceedings of the 3rd international conference on Intercultural collaboration. ACM, 2010.

[10] Aakash Agarwal, Kumar Abhishek, Vivek Kumar, Vineet Kumar, Nikhil Parsad and M. P. Singh "Dr. Eye: An Android Application to Calculate the Vision Acuity." Procedia Computer Science 54 (2015): 697-702.

[11] Kuei-Chun Lieu, Ching-Hung Wu, Shau-Yin Tseng and Yin-te Tsai "Voice Helper: A Mobile Assistive System for Visually Impaired Persons." Computer and Information Technology; Ubiquitous Computing and Communications; Dependable, Autonomic and Secure Computing; Pervasive Intelligence and Computing (CIT/IUCC/DASC/PICOM), 2015 IEEE International Conference on IEEE, 2015.

[12] Felix Burkhardt, Martin Eckert, Julia Niemenn, Frank Oberle, Thomas Sheerbarth and Stefen Seide "A mobile office and entertainment system based on android." Proceedings of the 21st Konferenz zu Elektronischer Sprachsignalverarbeitung (ESSV). 2010.

[13] Gaurang Kanvinde, Luz Rello, and Ricardo Baeza-Yates "IDEAL: a dyslexic-friendly ebook reader." Proceedings of the 14th international ACM SIGACCESS conference on Computers and accessibility. ACM, 2012.

[14] Sankar Mukherjee, and Shyamal Kumar Das Mandal "A Bengali speech synthesizer on Android OS." Proceedings of the 1st Workshop On Speech and Multimodal Interaction in Assistive Environments. Association for Computational Linguistics, 2012

[15] Jagmeet Kaur and Parminder Singh "Punjabi Speech Synthesis System for android mobile phones." 
International journal phones", International Journal of Engineering and Computer science 9 (2014).

[16] Arun Gopi, Shobhna Devi P, Sajini T and Bhadran V.K "Implementation of malayalam text to speech using concatenative based TTS for android platform." Control Communication and Computing (ICCC), 2013 International Conference on. IEEE, 2013.

[17] Sanja Primorac, and Mladen Russo "Android application for sending SMS messages with speech recognition interface." MIPRO, 2012 Proceedings of the 35th International Convention. IEEE, 2012.

[18] Shunji Mori, Hirobumi Nishida, and Hiromitsu Yamada. Optical character recognition. John Wiley \& Sons, Inc., 1999.

[19] Angelov, Krasimir, Björn Bringert, and Aarne Ranta. "Speech-Enabled Hybrid Multilingual Translation for Mobile Devices." EACL. Vol. 14. 2014.

[20] Krasimi Angelov, Bjorn Bringert and Arne Ranta "Building transcribed speech corpora quickly and cheaply for many languages." INTERSPEECH. 2010.

[21] Paulo A. Condado, and Fernando G. Lobo "EasyVoice: Integrating voice synthesis with Skype." Proceedings of the 9th international ACM SIGACCESS conference on Computers and accessibility. ACM, 2007.

[22] Yang, Zhuorui, James M. Schafer, and Aura Ganz. "Reliable and User Friendly US Banknote Recognition Application for Visually Impaired Users on Android
Smartphones." International Journal of E-Health and Medical Communications (IJEHMC) 5.3 (2014): 1-16.

[23] Yu, Ronald, Tong Lai Yu, and Ihab Zbib. "Animating TTS Messages in Android using OpenSource Tools." Proceedings of the International Conference on Computer Graphics and Virtual Reality (CGVR). The Steering Committee of the World Congress in Computer Science, Computer Engineering and Applied Computing (WorldComp), 2013.

[24] S. Saychum, A. Thangthai and P. Janjoi "A bi-lingual Thai-English TTS system on Android mobile devices." Electrical Engineering/Electronics, Computer, Telecommunications and Information Technology (ECTI-CON), 2012 9th International Conference on. IEEE, 2012.

[25] Yu Zhong, T.V. Raman, Casey Burkhardt, Fadi Biadsy and Jeffrey P. Bhigam "JustSpeak: enabling universal voice control on Android."Proceedings of the 11th Web for All Conference. ACM, 2014.

[26] J. Stent Amanda, Shiri Azenkot, and Ben Stern. "Iwalk: a lightweight navigation system for low-vision users." Proceedings of the 12th international ACM SIGACCESS conference on Computers and accessibility. ACM, 2010.

[27] A bar chart available on the online forum (2013, Dec) [Online]. Available: http://www.consumerforum.in.

[28] A power point by Vibhek (2016, Feb 10). Available: http://www.slideshare.com 